\title{
The Effect of Paraffin Treatment with Exercise on Muscle Strength and Fatigue of the Hand According to the Use of Smartphone
}

\author{
Su-Hyon Kim \\ Department of Physical Therapy, Hanlyo University, Gwangyang, Republic of Korea
}

Purpose: This study examined the effects of a paraffin treatment with exercise on the muscle strength and fatigue of the hand according to the use of smartphones.

Methods: The measurement subjects were 30 healthy males in their 20s who were divided randomly into the control and paraffin treatment groups. A typing exercise using a smartphone was performed. The pinch grip force was measured to evaluate the muscle strength of the thumb, and muscle fatigue analysis using electromyography was performed to analyze muscle fatigue.

Results: The functional changes to the arm and the fatigue of the hand through the use of a smartphone were examined to determine the effects of the paraffin treatment. The dominant hand-pinch grip force test did not show a significant difference, but the non-dominant hand-pinch grip force test showed a significant difference between the groups $(p=0.030)$. In the dominant hand fatigue test, there was a significant difference between the groups $(p=0.037)$. In the non-dominant hand, there was a significant difference between time $(p=0.012)$ and the groups $(p<0.001)$.

Conclusion: The effects of paraffin intervention on the hand muscle strength and fatigue due to repeated use of the smartphone were confirmed. These results can be used as a basis for clinical use and can be a guide for the correct use of smartphones, which are essential in modern life.

Keywords: Smartphone, Electromyography, Muscle fatigue, Paraffin treatment.

\section{서 론}

스마트폰 발달은 PC 기반의 인터넷 사용과 같이 고정된 특정 장소에 서만 이용해야 하는 한계를 벗어나 시간과 장소에 구애받지 않고 언 제 어디서나 편리하게 정보와 네트워크에 접근할 수 있는 생활이 가 능하게 되었다. 이러한 발달과 편리함 때문에 스마트폰을 이용하는 사람들의 숫자는 꾸준히 증가하는 추세이다. 대부분의 스마트폰 사 용자는 통화 기능과 정보이용을 포함하여 사용 시간이 1 일 1 시간 이 상이었고, 3 시간 이상도 $50 \%$ 로 보고되고 있다. 스마트폰 사용이 일 상생활에 도구로서 인체에 주는 영향이 매우 높아졌으며, 스마트폰 의 편리한 기능과 휴대성은 오히려 중독적 사용 같은 부정적인 현상 을 유발할 수 있다. 과도한 스마트폰 사용은 눈과의 거리와 사용시간 에 따라 심리적 부담과 정신 피로 등에 영향을 미치며, 심리적으로는 불안과 우울증을 유발할 수 있다. ${ }^{3}$
스마트폰 사용 시간이 길어질수록 인체의 이상 증상 및 근골격계 질환이나 통증을 발생에 영향을 미친다. ${ }^{4}$ 스마트폰 사용으로 인하여 인체에 발생할 수 있는 대표적인 질환으로는 목 통증, 시력저하, 안구 건조증과 손목터널증후군 등의 증상이 있으며,5,6 장기간의 잘못된 사용으로 자세의 변화를 가져온다.8. 과도한 힘이 요구되거나 반복적 인 동작은 근골격계 질환인 손목터널증후군을 유발하는 요인이 된 다. 스마트폰의 사용 시간 증가는 손가락 및 관절의 과다사용으로 반 복성 긴장성 증후군을 일으킬 수 있다. 반복성 긴장성 증후군은 신체 의 특정 부위를 과다하게 반복 사용하게 될 경우에 신경, 인대, 근육 등이 손상을 받는 질환을 통칭하는 용어이며, 누적 외상 증후군, 과 사용 증후군, 직업적 근골격계 질환 등으로도 표현된다. 반복성 긴장 성 증후군의 대표적 질환으로는 손목터널증후군, 드퀘르벵 증후군, 방아쇠수지 증후군 등이 있다. ${ }^{9}$ 스마트폰으로 문자, 채팅, 게임 등을 반복적으로 지속하면 손과 손가락에 과도한 스트레스가 발생될 수
Received Jul 7, 2020 Revised Aug 14, 2020

Accepted Aug 26, 2020

Corresponding author Su-Hyon Kim

E-mail kimssuhyon@hanmail.net
Copylight (C)2020 The Korean Society of Physical Therapy

This is an Open Access article distribute under the terms of the Creative Commons Attribution Non-commercial License (https:// creativecommons.org/license/by-nc/4.O.) which permits unrestricted non-commercial use, distribution, and reproduction in any medium, provided the original work is properly cited. 
있다. 손과 손가락의 과도한 사용은 팔에서 손으로 가는 신경이 손 인대에 눌려 저리거나 감각저하가 나타난다. ${ }^{10}$ 뿐만 아니라 지나친 스 마트폰 사용은 근육의 피로를 유발한다. 특히 팔의 대부분 근육과 어 깨와 손가락의 과부하가 발생하며, 질환으로 발전될 수 있다.1-13 스마 트폰 사용으로 인한 인체 관련 이상 증상은 시력저하, 안구건조증과 손목터널증후군 등의 증상이 대표적이며, 습관적인 사용에 따른 중 독 증상을 나타낸다고 하였다.5.14

스마트폰 사용형태에 따른 3 차원 영상 분석, 근전도, 손가락 압력 측정기기 등을 이용한 연구결과에서 스마트폰의 사용형태가 엄지손 가락 관절의 가동성과 손목과 팔 근육의 활동에 영향을 미친다고 하 였으며. 특히 스마트폰 사용 시 입력 동작에서 주된 역할을 하는 엄 지손가락은 근육의 피로가 많이 발생하여 손의 기능을 떨어뜨린다.15

파라핀욕은 신체 국소 부위 불규칙한 표면에 미네랄과 파라핀 혼 합물을 사용한다. 전도열로서 융점이 높고 열전도가 낮은 점을 치료 에 이용하고 있다.16 파라핀의 적응증에는 관절염, 류머티즘 관절염, 골절이나 삔 후의 관절 경직, 급성기를 지난 윤활낭염, 섬유염, 힘줄 염, 과도긴장 등이 있으며, ${ }^{17}$ 파라핀의 효과로는 국소 충혈효과와 관 절이 굳어졌을 때 유연하게 만들어 운동과 마사지 전 단계에 사용되 며, 신진대사촉진, 혈액순환, 혈관 확장 등이 있다.16

따라서 본 연구는 반복적인 스마트폰 사용에 따른 손의 기능적 변 화와 손 근육의 과부하에 따른 피로도를 알아보기 위해 진행되었다. 또한 파라핀 치료가 손의 기능과 피로도에 미치는 영향을 알아보고 자하였다.

\section{연구 방법}

\section{1. 연구대상}

대상자는 보다 정확한 근전도 측정과 평가를 위하여 건강한 20대 성 인 남성 30 명으로 구성되었으며, 대조군과 파라핀 치료군에 무작위로 15 명씩 배정하였다. 대상자의 일반적 특성은 다음과 같다(Table 1).

\section{2. 실험방법}

1) 실험 설계

실험은 총 2 번의 타자 훈련과 4 번의 측정을 진행하였다. 타자 훈련은 Table 1. General characteristics

\begin{tabular}{lcc}
\hline & group I $(n=15)$ & group II $(n=15)$ \\
\hline Age $(\mathrm{yr})$ & $24.80 \pm 3.41$ & $25.13 \pm 2.72$ \\
Height $(\mathrm{cm})$ & $173.33 \pm 5.29$ & $171.87 \pm 5.63$ \\
Weight $(\mathrm{kg})$ & $69.13 \pm 6.57$ & $67.00 \pm 7.07$ \\
Smartphone usage time & $4.20 \pm 1.37$ & $4.53 \pm 1.53$ \\
Dominant/non-dominant & Rt: $13 / \mathrm{Lt}: 2$ & $\mathrm{Rt}: 12 / \mathrm{Lt}: 3$ \\
\hline
\end{tabular}

group l: control group, group II: paraffin treatment group combined with exercise.
1 회와 2 회로 나누고 회당 시간은 각 30 분씩 진행하였으며, 1 차 타자 측정 후 약 2 분간 휴식하였다. 핀치 그립력과 근전도 측정은 타자 측 정 전 1 차 측정, 1 차 타자 연습 후 2 차 측정, 2 차 타자 연습 후 3 차 측정 을 진행하였다. 4 차 측정 전에 대조군은 30 분간 휴식, 실험군은 30 분 간 파라핀 치료 후에 4 차 측정을 실시하였다.

\section{2) 측정도구 \\ (1) 스마트폰}

스마트폰을 이용한 타자 연습은 크기 가로 $69.6 \mathrm{~mm}$, 세로 $142.4 \mathrm{~mm}$, 두께 $7.9 \mathrm{~mm}$ 이며, 무게는 $152 \mathrm{~g}$ 의 무게를 가진 갤럭시 S7 스마트폰 기 기(SM-G930, Samsung Electronics, Korea)를 사용하였으며 타자 프로 그램으로 안드로이드 기반의 앱인 NC 타자 연습(NJC: Korea)을 사용 하였다.

실험대상자의 스마트폰 사용 자세는 앉은 자세에서 팔꿉관절 120 도 굽힌 자세에서 양손을 이용하여 스마트폰 타자 연습을 시행하였 으며, 스마트폰과 얼굴의 거리는 약 $30 \mathrm{~cm}$ 로 하였다.

본 연구의 보다 객관적인 결과를 위해 공통된 하나의 기종의 스마 트폰으로만 실험하였다. ${ }^{8}$

\section{(2) 핀치 그립}

핀치 그립력을 측정하기 위해 핀치 그립 측정기(Baseline Digital Gauge Function 12-0237, Baseline ${ }^{\circledR}$, USA)를 사용하였다. 검사 자세는 외부의 힘을 최소화하기 위해 바로 선 자세에서 시선은 정면을 향하게 하고, 측정 시 일어날 수 있는 불필요한 운동을 등척성 수축을 이용하였다. 몸의 흔들림이나 반대 측 팔의 움직임을 제한하여 대상작용을 방지 하였다. 측정자는 측정기구를 쥐고 연구대상자의 손의 움직임을 방 지하기 위하여 가볍게 측정계를 받쳐주고 순간적인 최대 힘을 얻기 위해 집기 자세를 취한 후 '힘'이라는 구두지시를 이용하였다.

\section{(3) 근전도를 이용한 피로도 분석}

근전도 신호의 수집을 위해 표면 근전도기의 smaple rate는 $1,000 \mathrm{~Hz}$ 이 고 bandpass는 20-450Hz인 Bagnoli 4-EMG system (Delsys Inc., USA)를 사용하였다. 기록전극으로 DE-2.1 single differential electrode (Delsys Inc., USA)을 사용하였다. 근전도 신호의 수집을 위하여 대상자의 엄 지 두덩근에 표면 전극을 테이프를 사용하여 부착하여 기록하였다.

대상자의 정량화된 데이터 취득을 위하여 일정한 힘을 줄 수 있도 록 연습후에 측정을 하였다. 핀치 그립의 측정과 함께 최대 등척성 수 축력을 측정과 함께 근전도를 이용하여 데이터를 취득하였다. 자세 는 최대 집기력 측정 시에 이용했던 자세를 그대로 설정하였다.

근전도 측정은 핀치 그립력이 최고치의 $50 \%$ 수준으로 떨어질 때까 지 측정하였다. 저장된 근전도 신호를 대상으로 피로가 발생할 때까 
지의 중앙주파수(MDF) 분석을 통하여 피로 지수를 구하였다.

피로지수는 최대 등척성 수축력이 $100 \%$ 에서 $50 \%$ 이하 수준으로 떨어질 때까지 구간에서 최초 중앙주파수와 마지막 중앙주파수 값 을 구한 후 다음과같은 공식에 의해 구했다.

$$
\text { 피로지수(F.I) }=\frac{\text { 최초중앙주파수-마지막중앙주파수 }}{\text { 초기중앙주파수 }}
$$

3) 파라핀 치료

파라핀 치료를 실시하기 전에 초의 융점을 약간 낮추기 위하여 초와 미네랄 오일의 비율을 7:1 로 혼합하여 사용하였다. 측정 부위에 상처 난 곳이나 이상 부위가 없는지를 확인하여, 따듯한 물로 비누를 사용 해 씻은 뒤 완전히 마른 후에 적용하였다. 파라핀욕에 손을 3초간 담 궜다 뺐다. 10 초 동안 막이 형성되는 시간을 두어 다시 담궜다. 이 과 정을 10 회 반복하였다. 손을 빼낸 뒤 손가락을 편 상태로 15 분간 유지 하였다. 충분히 굳은 파라핀을 벗겨내 손가락 굽힘-폄 운동을 3 분간 실시하였다.

\section{3. 자료 분석}

본 연구에서 측정된 실험결과의 자료처리는 SPSS 25.0 통계 프로그램 을 이용하였으며, Kolmogorov-smirnov 검정 결과 얻어진 데이터가 정 규성을 보여 모수 검정을 적용하였다. 핀치 그립력과 엄지두덩근의 피로도 분석에 대한 시기에 따른 군 간의 비교를 위해 반복측정 분산 분석(Repeated Measures ANOVA)을 실시하였다. 모든 통계처리에 대 한 유의수준은 $\alpha=0.05$ 로 설정하였다.

Table 2. Change of pinch grip force between group on dominant hand

(kg)

\begin{tabular}{lccc}
\hline time/ group & group I & group I & $p$ \\
\hline I & $21.41 \pm 3.41$ & $20.39 \pm 2.64$ & \\
II & $20.08 \pm 3.85$ & $20.79 \pm 3.40$ & time: 0.244 \\
III & $18.92 \pm 2.97$ & $20.65 \pm 3.84$ & time $\times$ group: 0.334 \\
IV & $18.59 \pm 3.09$ & $20.07 \pm 3.21$ & \\
\hline
\end{tabular}

group I: control group, group II: paraffin treatment group combined with exercise, I : pre, II : post 1st typing, III: post 2nd typing, IV: post treatment.

Table 3. Change of pinch grip force between group on non-dominant hand

(kg)

\begin{tabular}{lccc}
\hline time/ group & group I & group I & $p$ \\
\hline I & $21.87 \pm 3.35$ & $20.06 \pm 4.29$ & \\
II & $19.60 \pm 2.83$ & $21.06 \pm 3.09$ & time: 0.727 \\
III & $19.39 \pm 3.32$ & $22.05 \pm 2.73$ & time $\times$ group: 0.126 \\
IV & $18.66 \pm 2.71$ & $21.06 \pm 2.56$ & \\
\hline
\end{tabular}

group I: control group, group II: paraffin treatment group combined with exercise, I: pre, II: post 1st typing, III: post 2nd typing, IV: post treatment.

${ }^{*} p<0.05$.

\section{결 과}

\section{1. 우세손의 핀치 그립력의 시기에 따른 군 간 변화}

우세손의 핀치 그립력의 시기에 따른 군 간 변화에서 시기, 시기×군, 군 모두에서 유의한 차이를 보이지 않았다(Table 2).

\section{2. 비-우세손의 핀치 그립력의 시기에 따른 군 간 변화}

비-우세손의 핀치 그립력의 시기에 따른 군 간 변화에서 군 간의 유의 한 차이를 나타냈으며 $(\mathrm{p}=0.030)$, 시기, 시기 $\times$ 군에서는 유의한 차이 를 보이지 않았다(Table 3).

\section{3. 우세손의 엄지두덩근 피로도의 시기에 따른 군 간 변화}

우세손의 엄지두덩근 피로도의 시기에 따른 군 간 변화에서 군 간의 유의한 차이를 나타냈으며 $(\mathrm{p}=0.037)$, 시기, 시기 $\times$ 군에서는 유의한 차이를 보이지 않았다(Table 4).

\section{4. 비-우세손의 엄지두덩근 피로도의 시기에 따른 군 간 변화}

비-우세손의 엄지두덩근 피로도의 시기에 따른 군 간 변화에서 시기 $(\mathrm{p}=0.012)$ 와 군 간 $(\mathrm{p}<0.001)$ 의 유의한 차이를 나타냈으며, 시기 $\times$ 군 에서는 유의한차이를 보이지 않았다(Table 5).

Table 4. Change of fatigue between group on the dominant hand thenar muscle

\begin{tabular}{lccc}
\hline time/ group & group I & group I & $p$ \\
\hline I & $0.25 \pm 0.03$ & $0.25 \pm 0.03$ & \\
II & $0.25 \pm 0.03$ & $0.24 \pm 0.03$ & time: 0.114 \\
III & $0.25 \pm 0.03$ & $0.23 \pm 0.03$ & time $\times$ group: 0.595 \\
IV & $0.27 \pm 0.04$ & $0.25 \pm 0.04$ & \\
\hline
\end{tabular}

group l: control group, group II: paraffin treatment group combined with exercise, I : pre, II: post 1st typing, III: post 2nd typing, IV: post treatment. ${ }^{*} \mathrm{p}<0.05$.

Table 5. Change of fatigue between group on the non-dominant hand thenar muscle

\begin{tabular}{lccc}
\hline time/ group & group I & group II & $\mathrm{p}$ (post hoc) \\
\hline I & $0.25 \pm 0.04$ & $0.24 \pm 0.03$ & time: $0.012^{*}$ \\
II & $0.26 \pm 0.03$ & $0.23 \pm 0.04$ & time $\times$ group: 0.200 \\
III & $0.26 \pm 0.03$ & $0.23 \pm 0.03$ & group: $<0.001^{* * *}$ \\
IV & $0.27 \pm 0.03$ & $0.25 \pm 0.03$ & $(\mathrm{a}, \mathrm{b})$ \\
\hline
\end{tabular}

group I: control group, group II: paraffin treatment group combined with exercise, I : pre, II: post 1st typing, III: post 2nd typing, IV: post treatment, a: difference between pre and post intervention, $b$ : difference between post 1st typing and post intervention.

${ }^{*} \mathrm{p}<0.05,{ }^{* * *} \mathrm{p}<0.001$ 


\section{고 찰}

본 연구는 건강한 20 대 성인을 대상으로 반복적인 스마트폰의 사용 이 손의 기능에 가장 중요한 부분을 차지하는 엄지 손가락 근육의 근 력을 통한 손의 근력과 피로도에 미치는 영향에 대해 알아보고자 하 였다.

스마트폰을 이용한 문자 입력 및 게임을 이용할 때, 손가락 가운데 가장 많이 사용하는 것은 엄지손가락이며, 양손 엄지 손가락의 동시 사용이 $46.1 \%$, 한 손 엄지 손가락 사용이 $36.2 \%$ 였다. 또한, 손의 복잡 하고 정교한 기능에서 집기 동작은 일상생활에서 필요로 하는 여러 동작 가운데 기본이 되고, 중요한 역할을 한다. ${ }^{18}$ 또한 스마트폰 사용 으로 인하여 인체의 통증을 호소하는 부위는 목, 어깨, 팔, 팔꿈치, 손, 손목, 손가락 등이 있었으며, 손 부위의 통증을 호소하는 비율이 가 장 높았다. ${ }^{19}$

손 기능을 평가할 때는 주로 파워 집기나 핀치 집기를 측정하는 데, ${ }^{20}$ 일반적으로 큰 힘을 필요로 하는 작업 시에는 보통 파워 집기를 많이 사용하며, 작업 도구가 작거나 작업을 하는 물체가 작을 때에는 핀치 집기를 주로 한다. ${ }^{21}$ 이러한 집기 작업 시 손목의 자세는 아래팔 과 손목근육에 많은 영향을 준다.22 손목이 중립자세에서 벗어난 상 태에서 지속적으로 작업을 유지하게 되면 아래팔의 근육들이 지속 적으로 스트레스를 받게 된다. ${ }^{23}$ 성인과 어린 청소년을 대상으로 스마 트폰을 사용할 때 가장 많이 사용하는 엄지손가락 근력과 근 피로 한계를 측정하여 생체 역학적인 특성을 분석한 연구에서 실험 결과 수의적 최대 수축력과 피로한계가 모두 어린 청소년이 성인의 약 $50 \%$ 수준으로 매우크게 떨어진다고 하였다.

본 연구는 파라핀 적용에 따른 손의 기능을 평가하기 위하여 핀치 그립력을 평가하였다. 자극의 종류에 따른 영향에서 온각 자극 입력 은 촉각 자극 입력보다 악력, 기민성 그리고 손 기능을 더욱 증가시킨 다. 따라서 신경계 재활치료 및 산업 현장에서 상자와 손 기능 증가를 위해서는 적절한 감각자극의 적용이 도움이 된다고 하였다. ${ }^{24} \mathrm{Chen}$ 과 $\mathrm{Shis}^{25}$ 는 $34^{\circ} \mathrm{C}$ 로 고정된 온도의 물속에 손을 담그게 하여, 손의 표면 열을 증가시키는 방법으로 손의 기능을 평가하여, 근력과 기민성은 팔의 표면열이 증가함에 따라 동시적으로 증가한다고 하였다. Youn 과 $\operatorname{Park}^{26}$ 은 적외선치료가 뇌졸중 환자의 근 기능과 관절가동범위를 향상시킨다고 하였다. 파라핀 치료를 통한 손 기능을 평가하기 위한 연구에서 파라핀 치료와 적극적인 운동이 대상자의 손 기능 및 신체 기능 그리고 활동에 참여하는 능력 등을 유의하게 증가시켰다고 하 였다. ${ }^{27}$

본 연구에서도 파라핀 치료에 따른 핀치 그립력 측정에서 대조군 은 반복적인 스마트폰 타자 연습으로 인해 시간이 지날수록 감소하 였으나, 파라핀 치료군은 비-우세손의 핀치 그립력에서 군 간의 유의
한 차이를 보여 핀치 그립력이 유의하게 유지됨이 나타났다 $(\mathrm{p}=$ 0.030). 우세손에서는 유의한 차이를 나타내지 않았으나 비-우세손과 유사한 양상을 나타냈다.

근골격계 질환의 공통적인 원인은 근육의 과도한 사용으로 인한 근피로가 동반되는 것이다. 근육의 과도한 사용은 생리적 대사와 피 로물질에 의해 신경전달지연 등으로 동작의 속도가 느려 지고 근력 이 약화되며, 통증이나 강직 등이 나타날 수 있다. ${ }^{28}$ Park 등 ${ }^{12}$ 은 스마 트폰을 20 분 이상 사용하게 되면 근 피로도가 증가한다고 하였다. 따 라서 스마트폰 사용자는 스마트폰 사용 시 올바른 자세를 취하고, 중 간에 휴식과 스트레칭 등의 예방적 행동을 취하기를 권고한다고 하 였다.

스마트폰의 사용에 따른 반복적인 동작이 수행이나, 손의 자세와 근육의 부하 등의 생체역학적 연구는 표면 근전도를 이용하여 근육 의 피로를 신호처리를 통하여 분석이 통하여 이루어지고 있다. ${ }^{29}$ 중 앙주파수는 근전도 스펙트럼에서 중앙값을 의미하는 것으로, 근육 의 피로도가 높아지면 주파수 스펙트럼이 낮아진다. 중앙주파수 분 석방법은 근육의 피로에 대한 분석의 대표적인 방법으로 시간의 흐 름에 따른 근전도 신호의 주파수 분포에 대한 변화를 보여주는 지표 로써, 중앙주파수 값이 낮아지면 근육의 피로가 쌓였다고 해석할 수 있다. ${ }^{30}$ 근피로도를 측정하기 위한 중앙주파수의 활용은 높은 신뢰도 를 나타낸다. ${ }^{31}$

본 연구는 스마트폰의 사용으로 인한 손의 피로도에 파라핀 치료 가 미치는 영향을 분석하기 위해 중앙주파수를 이용한 피로도 분석 을 실시하였다. 파라핀 치료에 따른 엄지손가락 근육의 피로도 분석 에서 대조군은 반복적인 스마트폰 타자 연습으로 인해 시간이 지날 수록 피로도가 증가하였으나, 파라핀 치료군은 우세손에서 군 간의 유의한차이를 보여, 대조군에 피해 피로도가 적음을 확인할 수 있었 다 $(\mathrm{p}=0.037)$. 비-우세손에서도 시기 $(\mathrm{p}=0.012)$ 와 군 $(\mathrm{p}<0.001)$ 에서 유 의한차이를 보여 우세손과 비-우세손에서 모두 파라핀 치료에 따른 피로도의 감소를 확인할 수 있었다.

온열의 국소 적용은 혈류가 증가시키고 혈관 확장으로 통해 영양 소와 백혈구, 항체 등이 유입되며, 대사산물과 조직 파편을 배출시켜 염증 반응을 완화시킨다고 하였으며, 이 연구에서의 피로도 감소의 요인으로 사료된다. ${ }^{32}$ 이상의 결과로 볼 때 반복적인 스마트폰 사용에 따른 손의 근력과 피로도에서 파라핀 중재의 효과를 확인할 수 있었 으며, 임상적인 활용을 위한 근거 자료로 활용될 수 있을 것으로 생각 된다.

본 연구는 우세손과 비-우세손으로 구분하여 시간에 따른 손의 근력과 근피로도를 분석하였으나, 우세손과 비-우세손의 차이는 확 인할 수 없었으며, 스마트폰의 장기간 사용에 따른 손의 집기와 근력, 근 피로 등의 분석이 부족하였다. 앞으로의 연구에서 스마트폰을 사 
용하는 것에 대한 기능적인 측면의 분석을 통해 현대인의 생활에서 필수적인 스마트폰의 사용에 올바른 지침이 만들어졌으면 한다.

\section{REFERENCES}

1. Kim BN, Ko EJ, Choi HG. A study on factors affecting smart-phone addiction in university students: A focus on differences in classifying risk groups. Studies on Korean Youth. 2013;24(3):67-98.

2. Park JS. The variables in influencing on smart phone addiction in adolescents and college students. Dankook University. Dissertation of Master's Degree. 2011.

3. Hwang KH, Yoo YS, Cho OH. Smartphone overuse and upper extremity pain, anxiety, depression, and interpersonal relationships among college students. JKCA. 2012;12(10):365-75.

4. Eom SH, Choi SY, Park DH. An empirical study on relationship between symptoms of musculoskeletal disorders and amount of smartphone usage. KSMS. 2013;15(2):113-20.

5. Chen P, Maklad N, Redwine M et al. Dynamic high-resolution sonography of the carpal tunnel. AJR Am J Roentgenol. 1997;168(2):533-7.

6. Lee HJ. Neck pain and functioning in daily activities associated with smartphone usage. J Kor Phys Ther. 2016;28(3):183-8.

7. Son SM. The adverse effect of proprioceptive sense in head-neck according to smartphone usage. J Kor Phys Ther. 2018;30(2):54-7.

8. Kong YS, Kim YM, Shim JM. Effects of modified cervical exercise on respiratory functions in smartphone users with forward head posture. J Kor Phys Ther. 2016;28(5):292-6.

9. Lee HG. Detection of varialbe predicting addicted use of mobile phone. Kor J of Soc Pers Psychol. 2008; 22(1):133-57.

10. Kim DS, Chae WS. Biomechanical analysis of a smartphone task with different postures. KJSB. 2012;22(2):253-9.

11. Moon YJ. Changes of upper extremity muscle on the hourly with smartphone use - focused on muscle activity and median frequency. J Kor Entertain Int Asso. 2015;9(3):341-8.

12. Park JH, Kang SY, Jeon HS. The effect of using smart-phones on neck and shoulder muscle activities and fatigue. PTK. 2013;20(3):19-26.

13. Lee NK, Son SM. The influence of hand muscle fatigue and fatigue recovery on joint position sense in healthy subjects. J Kor Phys Ther. 2014;26(6):425-9.

14. Kim JS, Cho KJ, Song JS. Influences of computer works on blink rate and ocular dryness in adolescents. J Korean Ophthalmol Soc. 2007;48 (11):1466-72.

15. Park JH, Kim GH, Son K. Comparison of muscular endurance limit of the thumb with repetitive using between adults and children. J Biomed Eng Res. 2013;34(1):1-7.
16. Park JC. Hydrotherapy. Seoul, Hyunmoon, 2016:173-9.

17. Lee SJ. Intervetion for hydrotherapy \& aquatic rehabilitatin. Seoul, Hyunmoon, 2010:119-23.

18. Gold JE, Driban JB, Thomas N et al. Postures, typing strategies, and gender differences in mobile device usage: an observational study. Appl Ergon. 2012;43(2):408-12.

19. Perry KB, Hourcade JP. Evaluating one handed thumb tapping on mobile touchscreen devices. In Proc GI. 2008:57-64.

20. Mathiowetz V, Rennells C, Donahoe L. Effect of elbow position on grip and key pinch strength. J Hand Surg Am. 1985;10(5):694-7.

21. Imrhan SN. The influence of wrist position on different types of pinch strength. Applied Ergonomics. 1991;22(6):379-84.

22. O'Sullivan LW, Gallwey TJ. Upper-limb surface electro-myography at maximum supination and pronation torques: the effect of elbow and forearm angle. J Electromyogr Kinesiol. 2002;12(4):275-85.

23. Kapandji IA. The physiology of the joints, annotated diagrams of the mechanics of the human joints. New York, Churchill Livingstone, 1982:100-31

24. Rhee HS, Kim SJ, Yu JH. The difference of grip strength, upper limb dexterity, and hand function according to light touch and thermal sensory stimulus. JKAIS. 2011;12(6):2644-51.

25. Chen WL, Shih YC, Chi CF. Hand and finger dexterity as a function of skin temperature, emg, and ambient condition. Hum Factors. 2010;52(3):426-40.

26. Youn PS, Park SJ. Immediate effect of sustained stretching exercises with far infrared on the ankle range of motion and muscle tone in patients with stroke. J Kor Phys Ther. 2019;31(1):56-61.

27. Mancuso T, Poole JL. The effect of paraffin and exercise on hand function in persons with scleroderma: a series of single case studies. J Hand Ther. 2009;22(1):71-7.

28. Gustafsson E, Johnson PW, Hagberg M. Thumb postures and physical loads during mobile phone use - a comparison of young adults with and without musculoskeletal symptoms. J Electromyogr Kinesiol. 2010;20(1):127-35.

29. Jonsson P, Johnson PW, Hagberg M et al. Thumb joint movement and muscular activity during mobile phone texting - a methodological study. J Electromyogr Kinesiol. 2011;21(2):363-70.

30. Murata A, Ishihara H. Evaluation of shoulder muscular fatigue induced during mouse operation in a vdt task. IEICE Transactions on Information and Systems. 2005; E88D(2):223-9.

31. Ng JK, Richardson CA. Reliability of electromyographic power spectral analysis of back muscle endurance in healthy subjects. Arch Phys Med Rehabil. 1996;77(3):259-64.

32. Kwak H, Lee S, Kim SB. Therapeutic heat and cryotherapy in family medicine. J Korean Acad Fam Med. 2003;24(10):877-83. 